\title{
Bidirectional Dopamine Modulation of GABAergic Inhibition in Prefrontal Cortical Pyramidal Neurons
}

\author{
Jeremy K. Seamans, ${ }^{1}$ Natalia Gorelova, ${ }^{2}$ Daniel Durstewitz, ${ }^{3}$ and Charles R. Yang ${ }^{4}$ \\ ${ }^{1}$ Howard Hughes Medical Institute, Salk Institute for Biological Studies, La Jolla, California 92037, 2Department of \\ Psychology, University of British Columbia, Vancouver, British Columbia, V6E 1V5, Canada, 3Biopsychology, Ruhr- \\ University Bochum, D-44801 Bochum, Germany, and ${ }^{4}$ Neuroscience Discovery, Eli Lilly \& Co., Indianapolis, Indiana \\ 46285-0510
}

\begin{abstract}
Dopamine regulates the activity of neural networks in the prefrontal cortex that process working memory information, but its precise biophysical actions are poorly understood. The present study characterized the effects of dopamine on GABAergic inputs to prefrontal pyramidal neurons using whole-cell patchclamp recordings in vitro. In most pyramidal cells, dopamine had a temporally biphasic effect on evoked IPSCs, producing an initial abrupt decrease in amplitude followed by a delayed increase in IPSC amplitude. Using receptor subtype-specific agonists and antagonists, we found that the initial abrupt reduction was D2 receptor-mediated, whereas the late, slower developing enhancement was D1 receptor-mediated. Linearly combining the effects of the two agonists could reproduce the biphasic dopamine effect. Because D1 agonists enhanced
\end{abstract}

Working memory processes are regulated by dopaminergic and GABAergic systems in the prefrontal cortex (PFC), although it is presently unclear how dopamine modulates GABAergic activity. Tyrosine hydroxylase/dopamine (DA)-immunopositive terminals in the PFC form mainly symmetric synapses on dendrites of GABA-immunoreactive neurons in both the rat and monkey (Verney et al., 1990; Sesack et al., 1995, 1998; Erickson et al., 2000). The percentage of GABA-containing neurons showing such contacts was highest in layer VI and progressively decreased toward upper layers (Benes et al., 1993), emphasizing the importance of DA modulation within deep layers. Tyrosine hydroxylasepositive terminals were often found directly apposing parvalbuminlabeled dendrites (Sesack et al., 1998). Parvalbumin-positive interneurons are mainly of the wide arbor and chandelier or fastspiking subtype of interneuron (Kawaguchi, 1993; Kawaguchi and Kubota, 1997), which synapse close to the somata of pyramidal neurons and constitute the major subtype of interneurons in PFC. Accordingly, D1 receptor immunoreactivity was predominately found on parvalbumin-containing interneurons and was less common $(<10 \%)$ on calbindin-containing interneurons (Le Moine and

Received Jan. 9, 2001; revised Feb. 12, 2001; accepted Feb. 27, 2001.

J.K.S. was funded by the Howard Hughes Medical Institute. D.D. was funded by Deutsche Forschungsgemeinschaft Grants DU 354/1-1 and DU 354/2-1 in the Computational Neurobiology laboratory at the Salk Institute. Most of the data in this study were collected in the laboratory of Dr. Charles Stevens at the Salk Institute, and we thank him for his support. We also thank Dr. Stan Floresco for helpful discussions.

Correspondence should be addressed to Dr. Jeremy K. Seamans, Howard Hughes Medical Institute, Salk Institute for Biological Studies, 10010 North Torrey Pines Road, La Jolla, CA 92037. E-mail: jeremy@salk.edu.

Copyright $\odot 2001$ Society for Neuroscience $0270-6474 / 01 / 213628-11 \$ 15.00 / 0$ spontaneous (sIPSCs) but did not affect miniature (mIPSCs) IPSCs, it appears that D1 agonists caused larger evoked IPSCs by increasing the intrinsic excitability of interneurons and their axons. In contrast, D2 agonists had no effects on sIPSCs but did produce a significant reduction in mIPSCs, suggestive of a decrease in GABA release probability. In addition, D2 agonists reduced the postsynaptic response to a $\mathrm{GABA}_{\mathrm{A}}$ agonist. D1 and D2 receptors therefore regulated GABAergic activity in opposite manners and through different mechanisms in prefrontal cortex (PFC) pyramidal cells. This bidirectional modulation could have important implications for the computational properties of active PFC networks.

Key words: prefrontal cortex; $D 1$ receptor; D2 receptor; persistent activity; interneuron; patch-clamp

Gaspar, 1998; Muly et al., 1998), suggesting that dopamine may modulate certain types of inhibition in the PFC.

Dopamine is known to modulate GABA release in multiple brain regions. Electrically evoked, preloaded $\left[{ }^{3} \mathrm{H}\right] \mathrm{GABA}$ overflow was reduced by a D2 agonist in PFC, globus pallidus, and striatum (Penit-Soria et al., 1989; Rétaux et al., 1991; Floran et al., 1997; Harsing and Zigmond, 1997). Likewise, dopamine inhibited evoked GABAergic synaptic responses in striatal neurons, and this effect was blocked by a D2 antagonist (Delgado et al., 2000). In contrast, spontaneous release of $\left[{ }^{3} \mathrm{H}\right] \mathrm{GABA}$ was increased by D2 agonists in PFC (Rétaux et al., 1991), whereas dopamine also increased GABAergic spontaneous IPSCs (sIPSCs) recorded in PFC pyramidal neurons (Penit-Soria et al., 1987; Zhou and Hablitz, 1999). Using microdialysis, Grobin and Deutch (1998) showed that local administration of the D2 agonist via a dialysis probe resulted in a dose-dependent increase in extracellular endogenous GABA levels, whereas acute administration of a D2 antagonist weakly decreased extracellular GABA levels (Bourdelais and Deutch, 1994). The reasons for the different effects of dopamine on exogenous and endogenous GABA release are presently unclear. One way to better understand the role of DA in modulation of inhibition is to go from global measures of extracellular GABA levels to investigations of the effects of DA on synaptically released GABA onto single pyramidal cells in the PFC.

Functional interactions of dopamine and GABA in the PFC have also been examined in in vivo electrophysiological studies. Blockade of $\mathrm{GABA}_{\mathrm{A}}$ receptors by bicuculline eliminated the dopamine-mediated depression of spontaneous firing in many PFC pyramidal neurons recorded extracellularly (Pirot et al., 
1992). Bicuculline also disrupted spatial tuning of delay-active neurons during delayed response tasks, which are used to assess working memory in primates (Rao et al., 2000). Dopamine also modulates delay-period activity of PFC pyramidal neurons, by moderately increasing background firing but strongly enhancing delay-period activity (Sawaguchi et al., 1986, 1988, 1990a,b). However, it is not presently known whether this modulation is attributable to its direct actions on pyramidal neurons or indirectly via modulation of interneurons, or a mixture of both. Computational models of PFC delay-period activity predict that dopamine-mediated alterations in GABA currents in pyramidal cells are critical for maintaining the specificity of stored representations and to avoid spontaneous "pop-outs" or random initiation of sustained activity that would otherwise interfere with task performance (Durstewitz et al., 1999, 2000). Understanding how dopamine modulates inhibition onto pyramidal neurons would therefore provide important insights into its role in working memory functions of the PFC.

\section{MATERIALS AND METHODS}

Sprague Dawley and Long-Evans rats (14-28 d, Salk Colony) were lightly anesthetized with isoflurane or metafane. Their decapitated brains were rapidly dissected and immersed for $1 \mathrm{~min}$ in cold $\left(4^{\circ} \mathrm{C}\right)$ oxygenated (carbogen, $95 \% \mathrm{O}_{2}-5 \% \mathrm{CO}_{2}$ ) artificial CSF (ACSF) (in mM): $2.5 \mathrm{KCl}, 1.25 \mathrm{NaH}_{2} \mathrm{PO} 4,25 \mathrm{NaHCO}_{3}, 0.5 \mathrm{CaCl}_{2}, 6 \mathrm{MgCl}_{2}, 25$ dextrose, 1.3 ascorbic acid, 2.4 pyruvic acid, and $125 \mathrm{NaCl}$. Sucrose $(200 \mathrm{~mm})$ or choline $(110 \mathrm{~mm})$ was routinely substituted for $\mathrm{NaCl}$ to prevent excitotoxic damage resulting from severing axons during slicing. Slices $(300$ $\mu \mathrm{m})$ containing the prelimbic-infralimbic region of the PFC, flanked by the corpus callosum in coronal sections (Paxinos and Watson, 1982; Uylings and van Eden, 1990), were transferred to ACSF containing (in mM) $126 \mathrm{NaCl}, 3 \mathrm{KCl}, 26 \mathrm{NaHCO}_{3}, 3 \mathrm{MgCl}_{2}, 1 \mathrm{CaCl}_{2}$, and 10 glucose until use, or placed directly in recording solution containing (in $\mathrm{mM}$ ) 126 $\mathrm{NaCl}, 3 \mathrm{KCl}, 26 \mathrm{NaHCO}_{3}, 1.3 \mathrm{MgCl}_{2}, 2.3 \mathrm{CaCl}_{2}$, and 10 glucose. Submerged slices in the recording chamber were perfused with recording solution at a rate of $1-3 \mathrm{ml} / \mathrm{min}$ and viewed using differential interference contrast (DIC) optics. Recordings were made at $31-33^{\circ} \mathrm{C}$, but recordings made previously at $23^{\circ} \mathrm{C}$ yielded similar results. Layer $\mathrm{V}$ is the largest layer in the rat PFC, and pyramidal neurons are easily identified under DIC optics because they possess much larger pyramidal-shaped somas than in other layers. The objective was often removed and the fluid level was decreased during recordings to reduce capacitance. Thickwalled borosilicate pipettes (3-10 M $\Omega$ tip resistance) were used for whole-cell patch-clamp recordings and were filled with (in $\mathrm{mM}$ ): 130 $\mathrm{KMeSO}_{4}, 10 \mathrm{KCl}, 4 \mathrm{NaCl}, 1$ EGTA, $2 \mathrm{MgCl}_{2}, 10$ HEPES, 4 NaATP, 0.3 Tris-GTP, 14 phosphocreatine, and 2 QX-314. In some experiments, 130 $\mathrm{mm} \mathrm{CsCl}$ was substituted for $\mathrm{KMeSO}_{4}$ and $\mathrm{KCl}$. Pipettes were connected to the headstage of an Axoclamp-2B or Axopatch-200A or B amplifier (Axon Instruments, Foster City, $\mathrm{CA}$ ) with $\mathrm{Ag} / \mathrm{AgCl}$ wire. $\mathrm{An} \mathrm{Ag} / \mathrm{AgCl}$ reference wire or pellet was placed in the bath directly or through an agar bridge, and voltage shifts were corrected using offset. Voltage-clamp recordings were obtained in continuous single-electrode voltage-clamp mode and filtered at $1 \mathrm{kHz}$. Access resistance was monitored throughout by applying a $-10 \mathrm{mV}$ voltage step, and a $\pm 15 \%$ change was deemed acceptable. Signals were digitized by a Digidata 2000 analog-to-digital (A/D) board (Axon Instruments) or a PCI-MIO-16E1 A/D board (National Instruments, Newbury, UK).

Bipolar stimulating electrodes, constructed from sharpened epoxyinsulated tungsten wires (A-M Systems, Inc.), were positioned within 200 $\mu \mathrm{m}$ of the soma in layer V. Electrical stimuli consisted of a low-intensity square-wave pulse $(100-150 \mu \mathrm{sec})$ administered every $30-60 \mathrm{sec} . \mathrm{D}(-)$ or ( \pm )2-Amino-5-phosphonopentanoic acid (APV) $(50 \mu \mathrm{M})$ and 6,7dinitroquinoxaline-2,3-dione (DNQX) or 6-cyano-7-nitroquinoxaline2,3-dione (CNQX) $(10 \mu \mathrm{M})$ and sometimes 2-hydroxy-saclophen (100$200 \mu \mathrm{M})$ were applied constantly throughout the entire experiment to isolate $\mathrm{GABA}_{\mathrm{A}}$ IPSCs. No synaptic response was observed at the same stimulation intensity after subsequent coapplication of bicuculline, suggesting that IPSCs were GABA $_{\mathrm{A}}$ receptor-mediated.

For applications of dopamine, the drug was always made fresh and the carbogen line, which saturated the ACSF, was removed 1-2 min before introducing dopamine plus additional ascorbic acid $(10 \mu \mathrm{M})$ or Na-meta bisulfite $(0.1 \%)$ as antioxidants. Dopamine was then applied for 1.5-2 min. In other experiments, $10 \mu \mathrm{M}$ of the full D1 agonist ( \pm )-6-chloro-PB hydrobromide (SKF-81297) or the D2 agonist quinpirole were applied for $5 \mathrm{~min}$, except for data shown in Figure 2 in which the following D1 agonists were also used at varying concentrations $(0.5-50 \mu \mathrm{M})$ : ( \pm -SKF38393, $R(+)$-SKF-81297, or $R(+)$-SKF-82957 (Research Biochemicals, Natick, MA). No differences in the effects of these agonists were observed, so data were pooled. All D1 and D2 agonists were made fresh daily. Unused drugs were sometimes stored at $4^{\circ} \mathrm{C}$ and used the following day. During application, the microscope and overhead lights were extinguished, and the drugs were delivered for 3-5 min to the bath via an opaque syringe. In some experiments, described in Results, the D1 antagonist $R(+)-\mathrm{SCH}-23390$ or the D2 antagonists sulpiride or raclopride $(10 \mu \mathrm{M})$ were applied continuously to the slices.

All figures and statistics analyzed IPSCs except Figure 2, $B$ and $D$, which included both IPSC and IPSP data combined. Means and SEM are presented. Statistics compared the average of baseline values with the average of all drug response for the time interval reported in Results. Cells were not selected based on their response to a drug but included all cells that showed a stable baseline response. The response at each time point was normalized to the baseline predrug average using the following formula: normalized value $=100 \times($ raw value/baseline average value $)-$ 100 to give a percentage change for each value relative to the average baseline response at each time point.

For miniature IPSC (mIPSC) experiments, slices were bathed in ACSF containing 0.2-1 $\mu \mathrm{M}$ TTX, 10-20 $\mu \mathrm{M}$ CNQX, and 50-100 $\mu \mathrm{M}$ APV using patch electrodes containing CsCl. For mIPSCs, $10 \mathrm{sec}$ samples were taken every $30 \mathrm{sec}$ for a $5 \mathrm{~min}$ period before drug application and a 5 min period after drug application. Events occurring in clusters were calculated relative to the baseline preceding the initial mIPSC in the cluster. When analyzing mIPSCs, the postdrug period was derived from sampling acquired immediately after application of D2 agonists because the effects on evoked IPSCs (eIPSCs) were immediate. In contrast, because it took $\sim 10 \mathrm{~min}$ to observe D1 effects on eIPSCs (Fig. 2), the $5 \mathrm{~min}$ postdrug sampling period was delayed for $10 \mathrm{~min}$ after application of D1 agonists. For experiments assessing postsynaptic responses, the $\mathrm{GABA}_{\mathrm{B}}$ agonist baclofen $(1 \mathrm{~mm})$ was applied every $60 \mathrm{sec}$ via a puffer pipette placed near the soma. The puffer solution and ACSF contained $0.25-5 \mu \mathrm{M}$ TTX and $10 \mu \mathrm{M}$ CNQX. The GABA ${ }_{A}$ agonist muscimol $(10-50 \mu \mathrm{M})$ was likewise applied in a similar ACSF solution or a solution containing $10 \mu \mathrm{M} \mathrm{CNQX}, 50 \mu \mathrm{M} \mathrm{APV}$, and 100-200 $\mu \mathrm{M}$ 2-hydroxy-saclophen. In cases in which the latter solution was used, a stimulating electrode was placed near the cells to produce an eIPSC 500 msec before the puff of agonist was applied.

\section{RESULTS}

Pyramidal cells were recorded under whole-cell voltage clamp from layers III-V of the prelimbic cortex using electrodes containing QX-314 in the presence of APV and CNQX or DNQX to isolate $\mathrm{GABA}_{\mathrm{A}}$ IPSCs. Because the dopamine agonists used in the present study stimulated either D1/D5 receptors or D2/ D3/D4 receptors, we will refer to effects as involving D1 or D2 receptors to denote the main class of receptor rather than the specific receptor subtype.

\section{Dopamine has temporally biphasic effects on IPSCs}

Figure $1, A$ and $B$, shows the effect of dopamine on isolated eIPSCs in pyramidal neurons. In many cells, and on average, dopamine had biphasic effects on eIPSC amplitude, producing an initial suppression ( $\sim 20 \mathrm{~min}$ after application), followed by a prolonged increase ( $>20 \mathrm{~min}$ after application) (Fig. 1A,B). For the three doses of dopamine, repeated measures ANOVAs compared the average baseline IPSC amplitude with the IPSC amplitude during the initial depression and the IPSC amplitude during the later enhancement. With $1 \mu \mathrm{M}$ dopamine, eIPSC amplitude was constant for the baseline period versus 2-20 and 24-40 min after application. However, with $10 \mu \mathrm{M}$ dopamine there was a small but significant difference in eIPSC amplitude relative to baseline, $4-10 \min (-8.1 \pm 2 \%$ change from baseline $)$ after application versus $10-35 \min (9 \pm 8 \%$ change from base- 
Figure 1. Dopamine has temporally biphasic effects on eIPSCs. $A$, Representative traces from neurons voltage-clamped at $-45 \mathrm{mV}$ using QX-314-filled electrodes in the presence of APV and CNQX. Application of 10 (top) or 20 (bottom) $\mu \mathrm{M}$ dopamine initially depressed eIPSC amplitude (Dopamine 1) but subsequently increased amplitude (Dopamine 2) before recovery. $B$, Mean and SEM group data showing the change in eIPSC amplitude over time. Dopamine $(20 \mu \mathrm{M})$ produced an initial reduction (1) before an enhancement (2) in eIPSC amplitude. Inset, The effects were dose dependent. A significant $(p<0.05)$ biphasic change in eIPSC amplitude was observed at 10 and $20 \mu \mathrm{M}$ dopamine but not at $1 \mu \mathrm{M}$. $C$, Dopamine $(20 \mu \mathrm{M})$ had no effect on the response to focal puff application of the $\mathrm{GABA}_{\mathrm{B}}$ agonist baclofen (1 mM in ACSF; $n=7) . D$, Dopamine $(20 \mu \mathrm{M})$ produced a long-lasting decrease but no rebound increase in $R_{\text {in }}$, as assessed with intracellular voltage steps of $-10 \mathrm{mV}$.
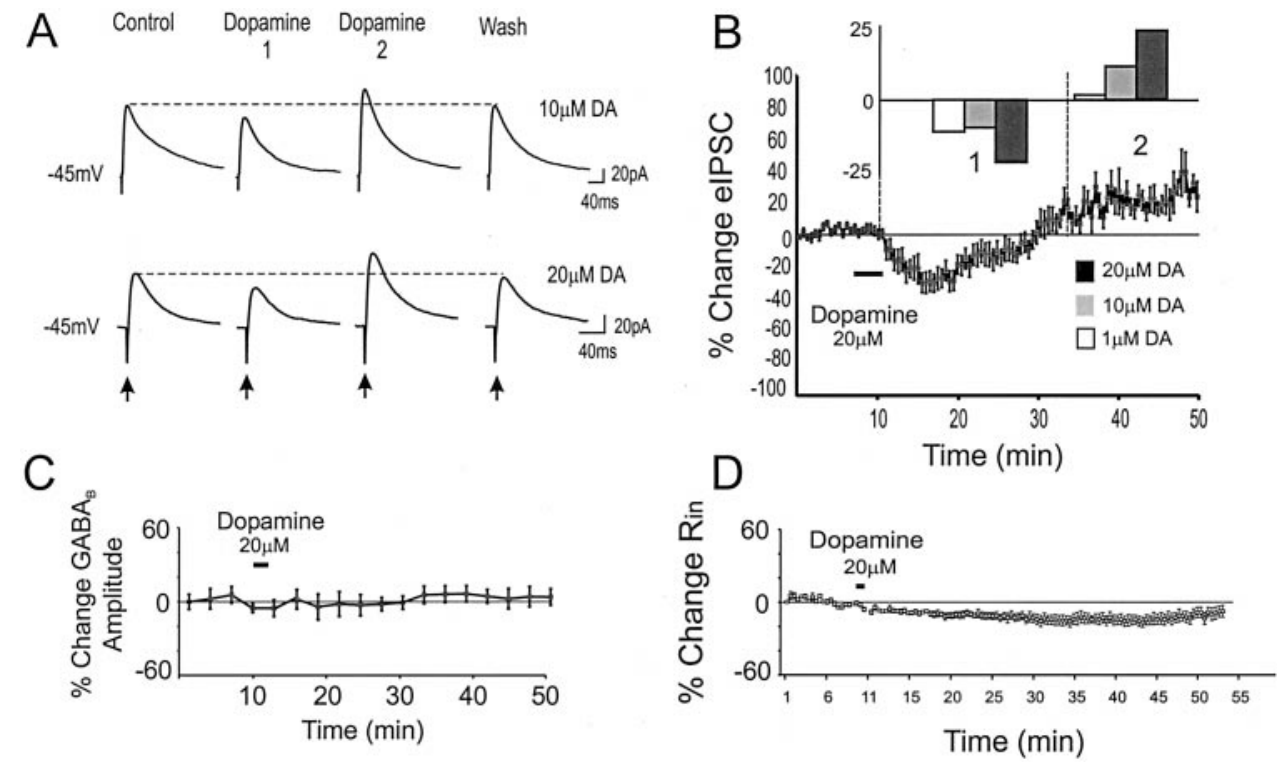

line) after application $(F=6.5 ; p<0.05 ; n=6)$ (Fig. $1 B)$. Likewise, with $20 \mu \mathrm{M}$ dopamine, there was a significant difference in eIPSC amplitude 4-20 min after application $(-18.2 \pm 5 \%$ change from baseline) versus $20-40 \mathrm{~min}$ (20.5 $\pm 9 \%$ change from baseline) after application $(F=22 ; p<0.01 ; n=20)$ (Fig. $1 B)$. In the $20 \mu \mathrm{M}$ dopamine condition, 10 of 20 cells showed the temporally biphasic response, 4 of 20 cells showed only the initial decrease, 2 of 20 cells exhibited only the late enhancement, and 4 of 20 cells showed no significant change. Thus, in most cells and overall, dopamine produced an initial dose-dependent decrease in eIPSC amplitude that was followed $\sim 10-20$ min later by an increase.

To probe possible effects of dopamine on $\mathrm{GABA}_{\mathrm{B}}$ receptors, we puffed the $\mathrm{GABA}_{\mathrm{B}}$ agonist baclofen $(1 \mathrm{~mm})$ onto the perisomatic region of layer $\mathrm{V}$ PFC neurons. As shown in Figure $1 C$, dopamine had no apparent effect on the $\mathrm{GABA}_{\mathrm{B}}$ response $(n=7)$. Because dopamine has been reported to produce a change in input resistance $\left(\mathrm{R}_{\text {in }}\right)$ (Shi et al., 1997; Gulledge and Jaffe, 1998; Gorelova and Yang, 2000), $\mathrm{R}_{\mathrm{in}}$ was monitored continuously in all cells. Figure $1 D$ shows that the average change in $\mathrm{R}_{\text {in }}$ was small and did not correlate with the biphasic change in IPSC amplitude. Thus, changes in $\mathrm{R}_{\text {in }}$ may affect the magnitude of the modulation but could not account for the biphasic action of dopamine on eIPSCs.

\section{D2 agonists decrease and D1 agonists increase IPSC amplitude}

Additional experiments were conducted to determine the contribution of the main classes of dopamine receptors to eIPSC modulation. Continuous application of a D1 antagonist (SCH$23390 ; 10 \mu \mathrm{M})$ prevented the late dopamine-mediated increase in eIPSC amplitude (Fig. 2A), leaving a clear decrease in eIPSC amplitude (baseline, $68 \pm 7.2 \mathrm{pA}$; dopamine plus D1 antagonist condition, $36.4 \pm 8 \mathrm{pA} ;-48 \pm 10 \% ; n=3)$. In contrast, continuous application of a D2 antagonist (sulpiride or raclopride; $10 \mu \mathrm{M}$ ) prevented the decrease in eIPSC amplitude by dopamine but produced only a small nonsignificant increase in IPSC amplitude (baseline, $92.8 \pm 8 \mathrm{pA}$; dopamine plus D2 antagonist, $102 \pm 13 \mathrm{pA} ; 14.8 \pm 12 \% ; F=1.5 ; p>0.2 ; n=12)$. To determine more directly the contribution of each dopamine receptor subtype, we applied specific D2 or D1 agonists. Bath application of a D2 agonist (quinpirole; $10 \mu \mathrm{M}$ ) produced an abrupt decrease in eIPSC amplitude (baseline, $49.2 \pm 7 \mathrm{pA}$; D2 agonist condition, $31.5 \pm 8 \mathrm{pA} ;-30 \pm 10 \%$ in the $4-30 \mathrm{~min}$ after application; $F=13.8 ; p<0.01 ; n=8$ ) (Fig. $2 B$ ). The depression peaked $\sim 15$ min after offset of quinpirole and showed $\sim 75 \%$ recovery after $30 \mathrm{~min}$. However, D2 agonists did not produce the late enhancement in eIPSC amplitude observed with dopamine. Similar results were obtained under current clamp in an additional five cells. The D2 agonist-mediated reduction in eIPSC amplitude was blocked by continuous coapplication of a D2 antagonist $(n=3)$ (Fig. $2 B)$.

In contrast, the D1 agonist caused a more slowly developing but sustained increase in eIPSC amplitude (baseline, $68.3 \pm 18 \mathrm{pA}$; D1 agonist condition, $88.3 \pm 18 \mathrm{pA}$, for the $10-40 \mathrm{~min}$ after application; $40 \pm 15 \% ; F=20.2 ; p<0.01 ; n=12$ ) (Fig. $2 C$ ). No differences were observed in the effects of $0.5-10 \mu \mathrm{M}$ versus $10-50$ $\mu \mathrm{M}$ D1 agonist $(F=0.5 ; p>0.8)$, so data were pooled. Similar results were obtained under current clamp in an additional nine cells. The increase in eIPSC amplitude by a D1 agonist was blocked by a D1 antagonist $(n=4)$ (Fig. $2 D)$. D1 agonists never produced the initial reduction in eIPSC amplitude observed after application of dopamine or a D2 agonist. Furthermore, the D1mediated increase generally was slower to develop, lasted for $>50$ min, and washed out in only 4 of 21 cells tested.

It is noteworthy that dopamine in the presence of a D2 antagonist (Fig. $2 A$ ) had a smaller effect on eIPSCs relative to the large and clear effect of the specific D1 agonist (Fig. 2C). One reason for this may be that only dopamine (and not the D1 agonist) decreased $\mathrm{R}_{\text {in }}$ (Gorelova and Yang, 2000) (Fig. 1D), thereby counteracting any potential increase in synaptic currents. Furthermore, both raclopride and sulpiride are relatively poor antagonists of the D4 receptor (Seeman and VanTol, 1994). Therefore, application of dopamine in the presence of these antagonists may have evoked the suppression of eIPSCs via activation of unblocked D4 receptors, which competed with the D1-mediated enhancement of eIPSCs. Although these hypotheses deserve further investigation, the present results nevertheless suggest that D2 agonists caused an abrupt decrease in eIPSC amplitude, 

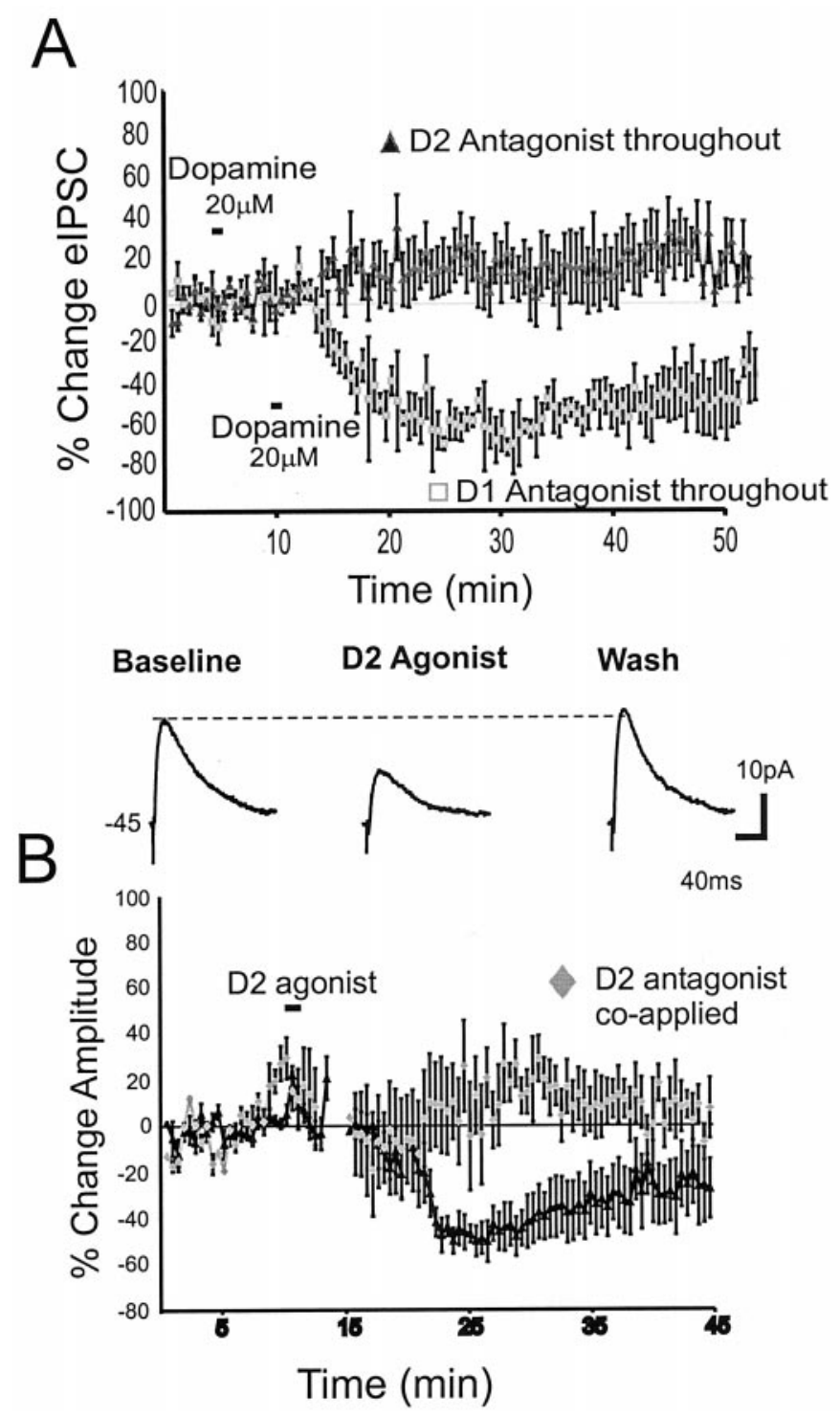
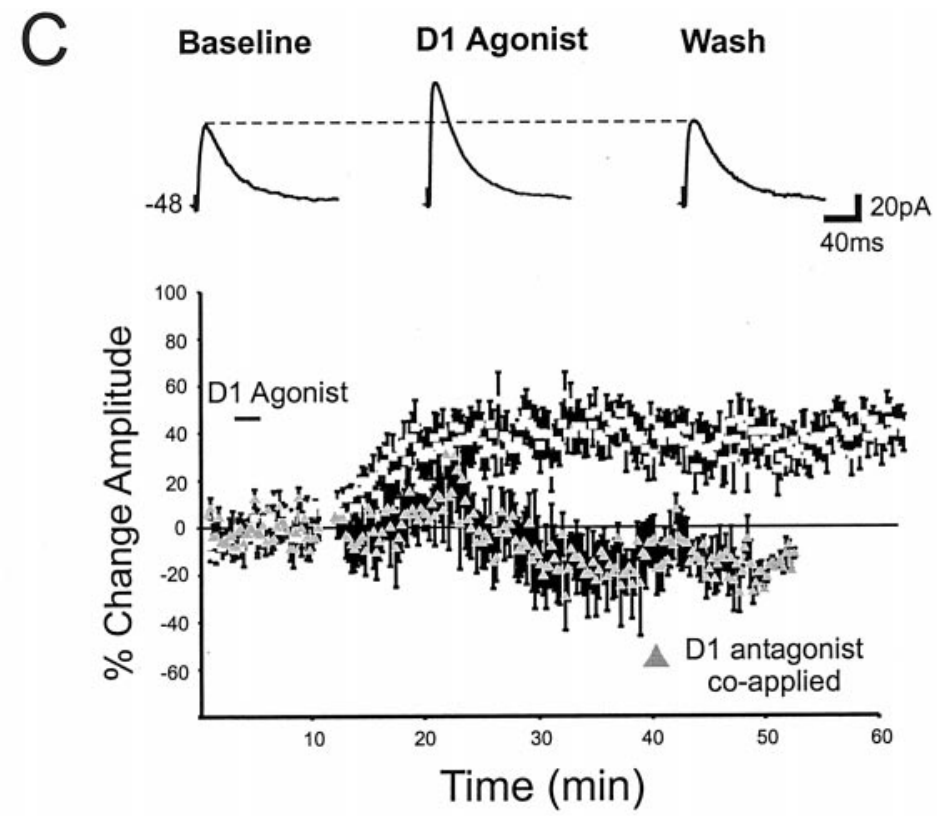

D

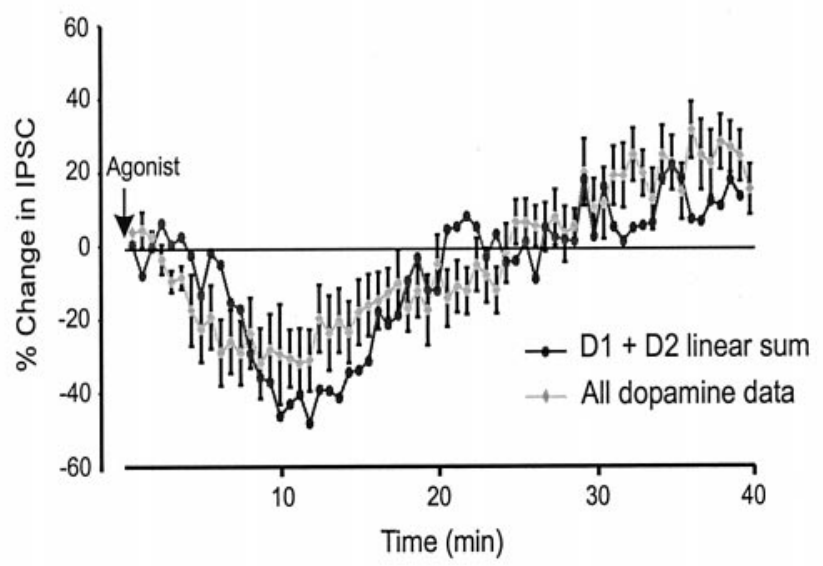

Figure 2. Dopamine agonist effects on eIPSC amplitude. A, Counterclockwise from top left, Application of dopamine (20 $\mu \mathrm{M})$ in the presence of a D1 antagonist (10 $\mu \mathrm{M} \mathrm{SCH}-23390)$ produced a pure depression of eIPSC amplitude ( gray triangles; $n=3$ ), whereas application of dopamine in the presence of a D2 antagonist $(10 \mu \mathrm{M}$ sulpiride or raclopride; $n=12)$ produced only a slight increase in eIPSC amplitude. $B$, Top, Representative traces showing that application of a D2 agonist (quinpirole $10 \mu \mathrm{M} ; n=8$ ) produced a pure decrease in eIPSC amplitude. Bottom, Mean and SEM group data showing that the D2 agonist reduced the average eIPSC amplitude (black triangles) and that this effect was blocked by coapplication of a D2 antagonist ( gray triangles). $C$, Top, Representative traces showing that application of a D1 agonist $(10 \mu \mathrm{M} \mathrm{SKF-81297;} n=12)$ produced a pure increase in eIPSC amplitude. Bottom, Mean and SEM group data showing that the D1 agonist increased the average eIPSC amplitude (black squares) and that this effect was blocked by coapplication of a D1 antagonist (gray triangles). D, The dopamine effect on eIPSCs ( gray triangles; $n=20$ ) is similar to the linear sum (black circles) of the effect of the D1 agonist and D2 agonist (graphs shown in $B$ and $C$ ) aligned to the time of drug offset.

whereas D1 agonists caused a more slowly developing but longer lasting increase in eIPSC amplitude.

Because the magnitude of the reduction and enhancement in eIPSC amplitude were larger for the pure agonists than for dopamine, it also suggested that coactivation of both receptors by dopamine had temporally offset but antagonistic effects on eIPSC amplitude. This seems indeed to be the case, as shown in Figure $2 D$ in which the linear sum of the D1 and D2 agonist curves (aligned to drug offset time) largely overlapped with the response curve for all cells in the dopamine condition.

\section{D1 agonists can reverse the effects of D2 agonists and} vice versa

If coactivation of D1 and D2 receptors by dopamine has simultaneous but antagonistic effects on IPSC amplitude, activation of one receptor class might reverse the effects of selective activation of the other receptor class and vice versa. This hypothesis was tested by first applying a D2 agonist briefly ( $5 \mathrm{~min}$ ) as in preceding experiments and then applying a D1 agonist for 5 min during the peak of the D2-mediated depression of eIPSCs. As shown in Figure 3, $A$ and $B$, the D2 agonist produced a suppression in eIPSC amplitude that could be reversed and turned into an increase in eIPSC amplitude by subsequent application of a D1 agonist $(n=7)$ (Fig. 3B, gray squares). Conversely application of a D1 agonist produced an enhancement in eIPSC amplitude that could be reversed by subsequent application of a D2 agonist and turned into a depression of eIPSC amplitude $(n=4)$ (Fig. 3A, $B$, black triangles). Therefore, dopamine can increase or decrease eIPSCs depending on the receptor subtype activated. 
A

Figure 3. eIPSC amplitude can be upregulated and downregulated by $\mathrm{D} 1$ and $\mathrm{D} 2$ agonists. $A$, Top, Representative traces showing that a D2 agonist produced a reduction in eIPSC amplitude that was reversed by a D1 agonist into an increase. Bottom, Representative traces showing that a D1 agonist produced an increase in eIPSC amplitude that was reversed by a $\mathrm{D} 2$ agonist into a decrease. $B$, Mean and SEM group data showing that the D1 agonist produced an increase in eIPSC amplitude that was changed to a decrease when followed 20 min later by a D2 agonist (black triangles; $n=7)$. Relative to the time scale on the graph, the D1 agonist was applied at 3-8 min, whereas the D2 agonist was applied at 27-30 min. The gray squares show the effects of the opposite experimental protocol whereby a D2 agonist was applied before a D1 agonist $(n=4)$. Relative to the time scale on the graph, the D2 agonist was applied at 8-15 min, whereas the D1 agonist was applied at $30-35 \mathrm{~min}$. The difference in application times for the two agonists in the two experiments was to control for the temporal differences in the effect of each drug (see Fig. 2B,C).

\section{Dopamine agonists have differential effects on sIPSCs}

sIPSC reflect IPSCs caused by both action potential-dependent and -independent release of GABA. In contrast, mIPSCs are recorded in TTX to eliminate the contribution of action potential-mediated release events. Therefore, a differential dopamine effect on sIPSCs and mIPSCs would indicate a selective effect on intrinsic interneuron excitability or modification of GABA release machinery, respectively. sIPSCs were recorded from pyramidal cells in layers III $(n=6)$ and V $(n=7)$. Excitatory transmission was blocked by adding APV and DNQX to the bath, whereas $\mathrm{Na}^{+}$currents and $\mathrm{K}^{+}$currents were blocked by inclusion of the lidocaine derivative $\mathrm{QX}-314$ and $\mathrm{CsCl}$ in the patch pipettes. The sI PSCs were recorded at holding potentials of -70 to $-80 \mathrm{mV}$ as inward currents because the high concentration of $\mathrm{Cl}^{-}$ions in the internal patch solution increased the reversal potential for IPSCs to approximately $-30 \mathrm{mV}$. These inward currents were blocked by adding the $\mathrm{GABA}_{\mathrm{A}}$ receptor antagonist bicuculline (10 $\mu \mathrm{M}$; data not shown).

Bath application of the D1 receptor agonists SKF-81297 (3-10 $\mu \mathrm{M})$ or dihydrexidine $(3-10 \mu \mathrm{M})$ induced a $44 \pm 18 \%$ increase in the frequency of sIPSCs in 9 of 13 pyramidal cells tested (control, $3.14 \pm 0.4$ events/sec; D1 agonist, $4.04 \pm 0.5$ events/sec; $F=11.5$; $p<0.01 ; n=13$ ) (Fig. $4 A, B$ ). In contrast, D1 agonists had no effect on sIPSC amplitude (control, $-39.6 \pm 8 \mathrm{pA}$; D1 agonist, $-37 \pm 7 \mathrm{pA}$ ). Because D1 agonists increased eIPSC amplitude and sIPSC frequency but not sIPSC amplitude, it suggested that D1 agonists increased the intrinsic excitability of interneurons or their axons. As a result, more axons were recruited when stimulated, yet the GABA release machinery and postsynaptic GABA receptors were not directly affected.
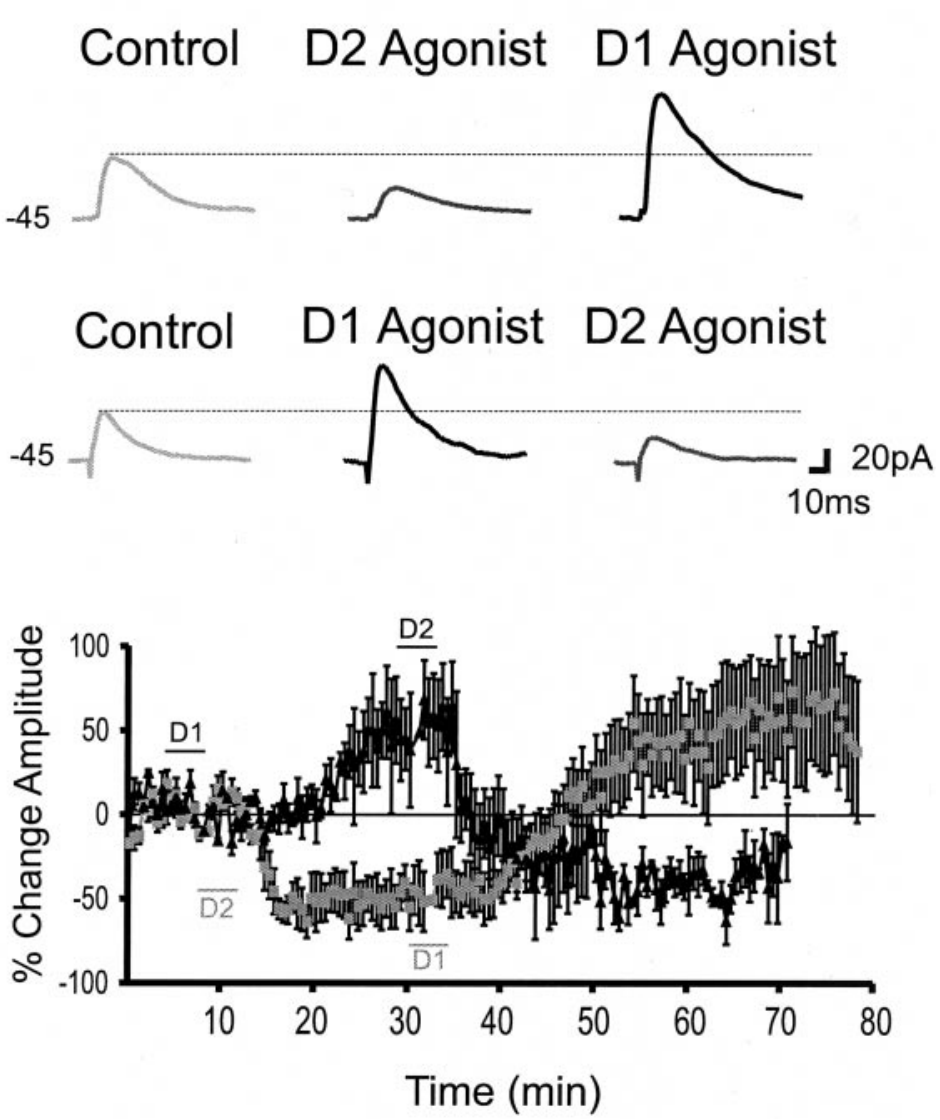

Bath application of the D2 agonist quinpirole $(10 \mu \mathrm{M})$ had nonsignificant effects on sIPSC frequency (control, $3.6 \pm 0.97$ events/sec; D2 agonist, $3.03 \pm 0.62$ events/sec; $F=1.98 ; p>0.05$; $n=5$ ) and amplitude (control, $-46.7 \pm 7 \mathrm{pA}$; D2 agonist, $-45.4 \pm 5.5 \mathrm{pA} ; F=0.1 ; p>0.5 ; n=5$ ) (Fig. $4 C, D)$.

\section{Dopamine agonists have differential effects on mIPSCs}

Changes in mIPSC frequency generally are taken to indicate a change in release probability, whereas changes in MIPSC amplitude suggest an alteration in postsynaptic receptor sensitivity or conductance. Unlike sIPSCs, mIPSCs were recorded in TTX to eliminate the contribution of action potential-mediated release events. mIPSCs recorded at holding potentials of $-70 \mathrm{mV}$ were inward currents and were blocked by adding the $\mathrm{GABA}_{\mathrm{A}}$ receptor antagonist bicuculline (10 $\mu \mathrm{M}$; data not shown).

mIPSCs frequency (control, $2.87 \pm 0.5$ events/sec; D1 agonist, $2.35 \pm 0.35$ events/sec; $F=4.4 ; p>0.06)$ and overall average amplitude (control, $-18 \pm 4.6 \mathrm{pA}$; D1 agonist, $-16.2 \pm 4 \mathrm{pA}$; $F=1.93 ; p>0.1 ; n=13$ ) were not altered significantly by the D1 agonist (Fig. 5A,B). Thus, although D1 receptor activation enhanced the frequency of spontaneous action potential-evoked releases, it did not significantly alter unitary release events or the postsynaptic currents they induced. This was expected if D1 agonists simply increased interneuron excitability.

In contrast, D2 agonists significantly reduced $\mathrm{mI}$ PSC frequency (control, $1.8 \pm 0.36$ events/sec; D2 agonist, $1.2 \pm 0.23$ events/sec; $-36 \pm 3.9 \% ; F=22 ; p<0.01)$ and overall average amplitude (control, $-14.5 \pm 2 \mathrm{pA} ; \mathrm{D} 2$ agonist, $-12.2 \pm 1.8 \mathrm{pA} ;-15.2 \pm$ $2 \% ; F=8.8 ; p<0.03 ; n=8$ ) (Fig. 5C,D). The reduction in mIPSC frequency suggested that D2 agonists reduced GABA 


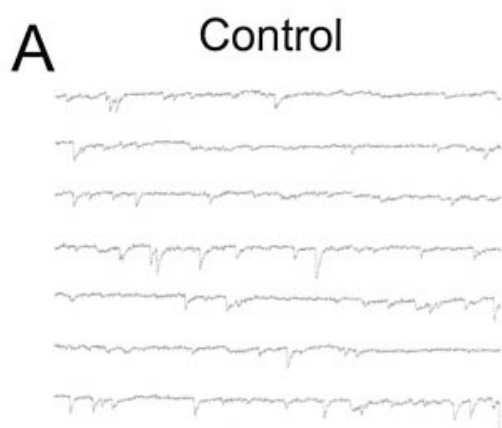

D1 Agonist

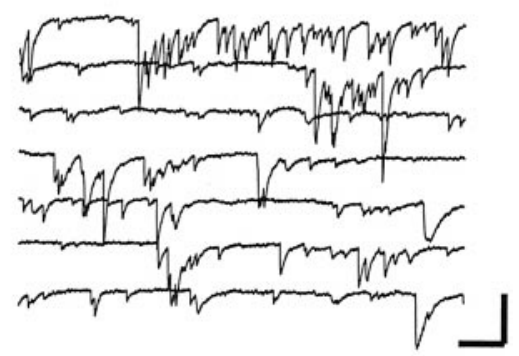

B

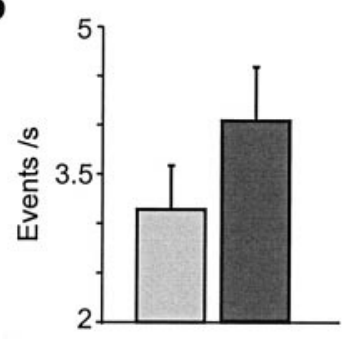

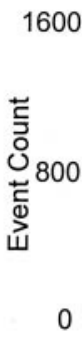

$0<20$
100-120

Event amplitude (20pA bins)

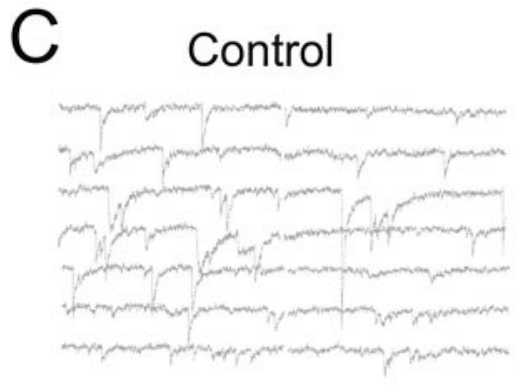

D

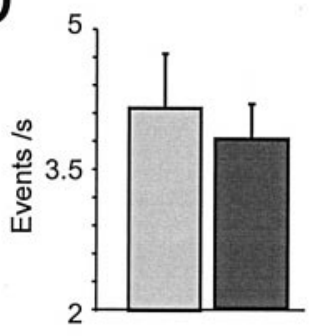

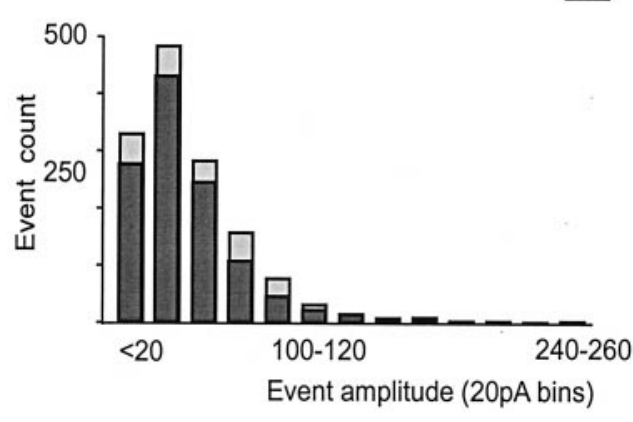

D2 agonist

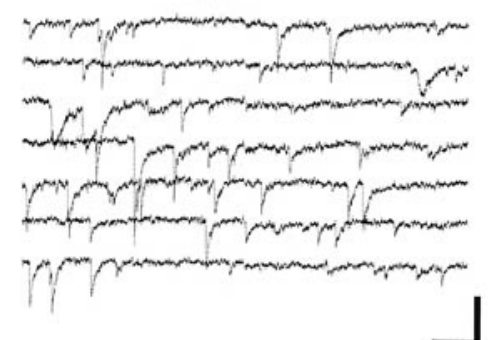

Figure 4. Dopamine agonist modulation of sIPSCs. $A$, Representative traces showing that the D1 agonist (black, right) increased the frequency of sIPSCs relative to the control condition (gray, left). Responses were recorded using CsCl- and QX-314-filled electrodes in the presence of APV and CNQX. Calibration: 100 pA, 600 msec. B, Left, Histogram of sIPSC frequency generated from all cells sampled for a $5 \mathrm{~min}$ period before D1 agonist application and for a $5 \mathrm{~min}$ period $10 \mathrm{~min}$ after D1 agonist application. D1 agonists increased sIPSC frequency. Right, Histogram from all cells showing the number of events in $20 \mathrm{pA}$ bins for the control condition (gray bars) versus the D1 agonist condition (black bars). $C$, Representative traces showing sIPSCs in the control condition ( gray, left) and after application of the D2 agonist (black, right). D, Left, Histogram of sIPSC frequency generated from all cells sampled for a 5 min period before D2 agonist application and for a $5 \mathrm{~min}$ period immediately after D2 agonist application. Right, Histogram from all cells showing the number of events in 20 $\mathrm{pA}$ bins for the control condition ( gray bars) versus the D2 agonist condition (black bars). D2 agonists had no significant effects on sIPSCs. release probability. However, D2 agonists reduced the frequency of larger mIPSCs ( $>10 \mathrm{pA})$, whereas mIPSCs $10 \mathrm{pA}$ in amplitude or smaller were actually slightly enhanced. Because the frequency of events was shifted to smaller amplitudes, the D2 agonist appeared to reduce either the postsynaptic sensitivity of $\mathrm{GABA}_{\mathrm{A}}$ receptors or the channel conductance.

\section{D1 and D2 modulation of postsynaptic GABA currents $_{A}$}

To more directly test the effects of dopamine agonists on postsynaptic $\mathrm{GABA}_{\mathrm{A}}$ currents, the $\mathrm{GABA}_{\mathrm{A}}$ agonist muscimol (20-50 $\mu \mathrm{M}$ ) was puffed on the perisomatic region of layer V PFC neurons (either $0.25-0.5 \mu \mathrm{M}$ TTX or $10 \mu \mathrm{M}$ CNQX and $50 \mu \mathrm{M}$ APV and
100-200 $\mu \mathrm{M}$ saclophen were included in the ACSF and puffer pipette). Although six of nine cells showed a clear increase in amplitude in the D1 condition, three of nine cells showed no difference, and overall the results missed significance because of high between-cell variance $(14 \pm 7 \% ; F=3 ; p>0.1 ; n=9)$ (Fig. $6 A$ ). Accordingly, the change in the postsynaptic $\mathrm{GABA}_{\mathrm{A}}$ current appeared to be too small to significantly influence sIPSC and mIPSC amplitude. In contrast the D2 agonist produced a $-18.5 \pm 7 \%$ decrease in the postsynaptic $\mathrm{GABA}_{\mathrm{A}}$ response in 9 of 11 cells $(F=5.5 ; p<0.04 ; n=11$ ) (Fig. $6 B)$. Collectively, these data show that $\mathrm{D} 1$ and $\mathrm{D} 2$ receptor activation differentially modulated the postsynaptic $\mathrm{GABA}_{\mathrm{A}}$ response. 


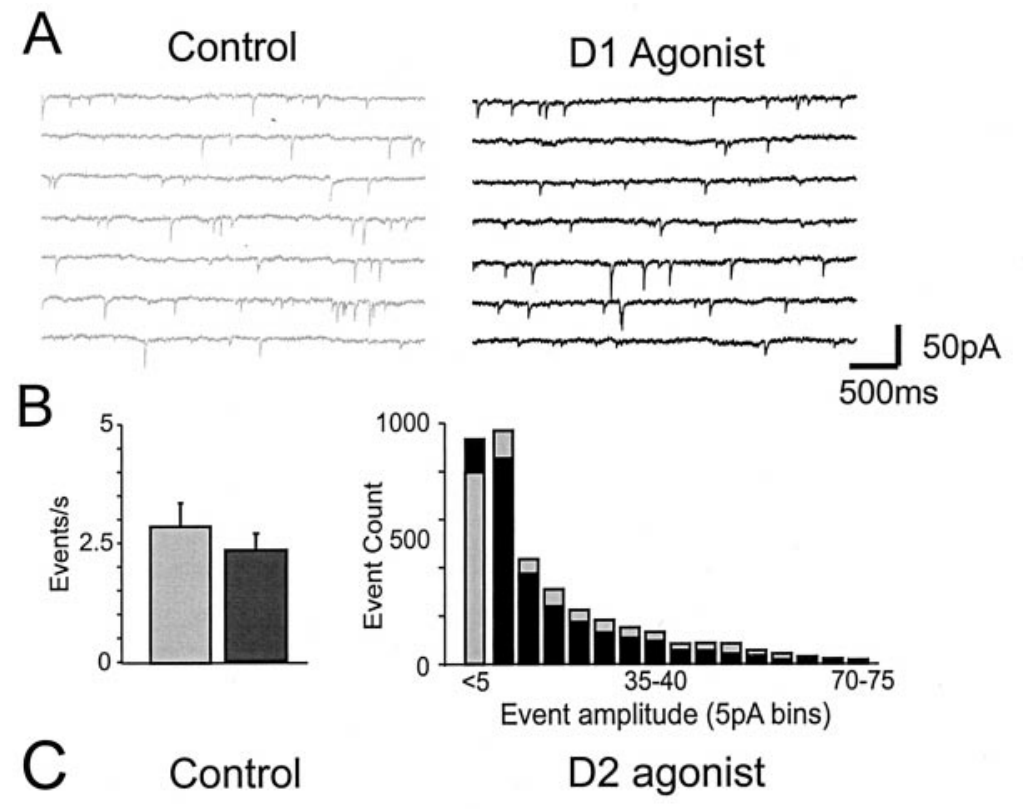

Figure 5. Effects of D1 and D2 agonists on mIPSCs. A, Representative traces showing mIPSCs in the control condition (gray, left) and after application of a D1 agonist (black, right). Responses were recorded using CsCl-filled electrodes in the presence of APV and CNQX and TTX. $B$, Left, Histogram of mIPSC frequency generated from all cells sampled for a 5 min period before D1 agonist application and for a $5 \mathrm{~min}$ period $10 \mathrm{~min}$ after D1 agonist application. Right, Histogram generated from all cells showing the number of events in $5 \mathrm{pA}$ bins for the control condition (gray bars) versus the D1 condition (black bars). D1 agonists had no effects on mIPSCs. $C$, Representative traces showing that the $\mathrm{D} 2$ agonist (black, right) decreased the frequency of mIPSCs relative to the control condition ( gray, left). D, Left, Histogram of mIPSC frequency generated from all cells sampled for a $5 \mathrm{~min}$ period before D2 agonist application and for a 5 min period immediately after D2 agonist application. Right, Histogram generated from all cells showing the number of events in $2.5 \mathrm{pA}$ bins for the control condition ( gray bars) versus the D2 condition (black bars). Inset, Same data replotted as a cumulative frequency plot to emphasize the leftward shift induced by a D2 agonist. D2 agonists decreased mIPSC frequency and amplitude.
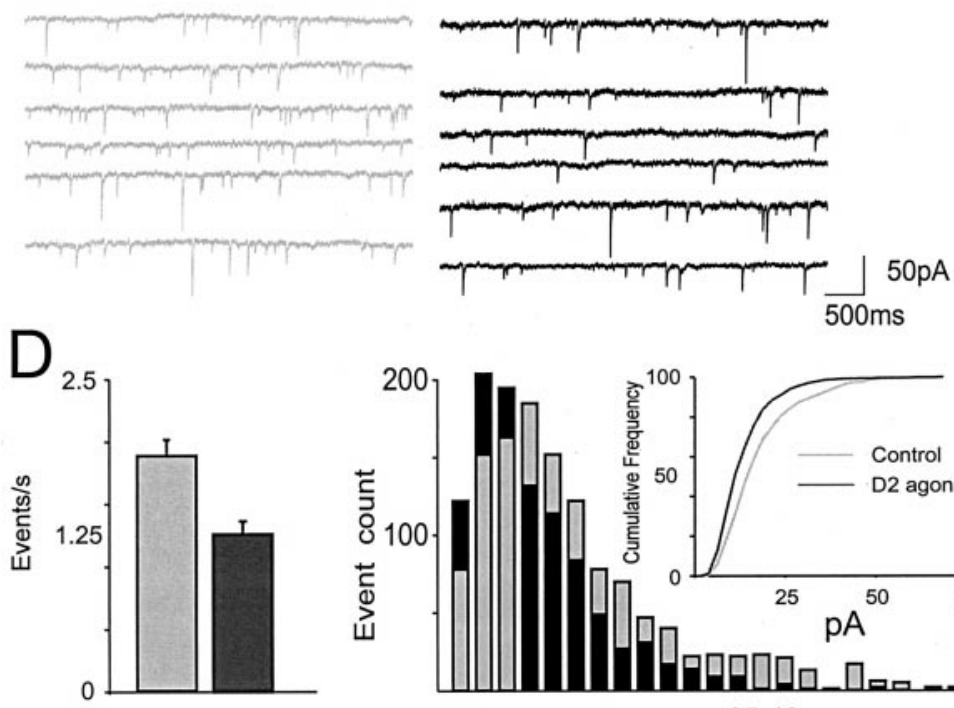

\section{DISCUSSION}

The present study found that dopamine produced temporally biphasic effects on fast $\mathrm{GABA}_{\mathrm{A}}$-mediated eIPSCs in pyramidal neurons of the PFC but had little effect on $\mathrm{GABA}_{\mathrm{B}}$ currents. Dopamine produced an initial reduction in eIPSCs mediated by D2 receptors, followed by a delayed and long-lasting increase in eIPSC amplitude mediated predominately by D1 receptors. Based on the effects of dopamine and D1 agonists in the present study and on data from direct interneuron recordings (Zhou and Hablitz, 1999; N. Gorelova, J. Seamans, and C. Yang, unpublished observations), it appears that the enhancing effect of D1 receptor activation on eIPSCs is mainly attributable to a D1mediated increase in the intrinsic excitability of interneurons. In addition, D1 stimulation also increased the amplitude of postsynaptic $\mathrm{GABA}_{\mathrm{A}}$ currents, although this effect was too small to influence sIPSC and mIPSC amplitudes. The D2-mediated reduction in eIPSC amplitude, on the other hand, appeared to be mediated by both a presynaptic reduction in release and a small postsynaptic reduction in $\mathrm{GABA}_{\mathrm{A}}$ receptor sensitivity or conductance. This presynaptic and postsynaptic GABA modulation by D1 and D2 receptors is consistent with anatomical data showing that parvalbumin-positive fast-spiking interneurons, which according to Kawaguchi (1993) constitute the major class of interneurons in the PFC, are immunopositive for both D1 and D2 receptors on presynaptic (axonal) and postsynaptic (dendritic) locations (Sesack et al., 1995, 1998; Le Moine and Gaspar, 1998; Muly et al., 1998).

\section{Bidirectional effects of dopamine}

The temporally biphasic effects of dopamine on eIPSC amplitude largely overlapped with the linear sum of the individual D2 and D1 agonist experiments and were mimicked qualitatively by application of a D2 agonist followed 20 min later by application of a D1 agonist. Although the dopamine effect was qualitatively similar to the linear sum of D1 and D2 agonist effects, the early reduction and late enhancement of eIPSC amplitude by dopa- 

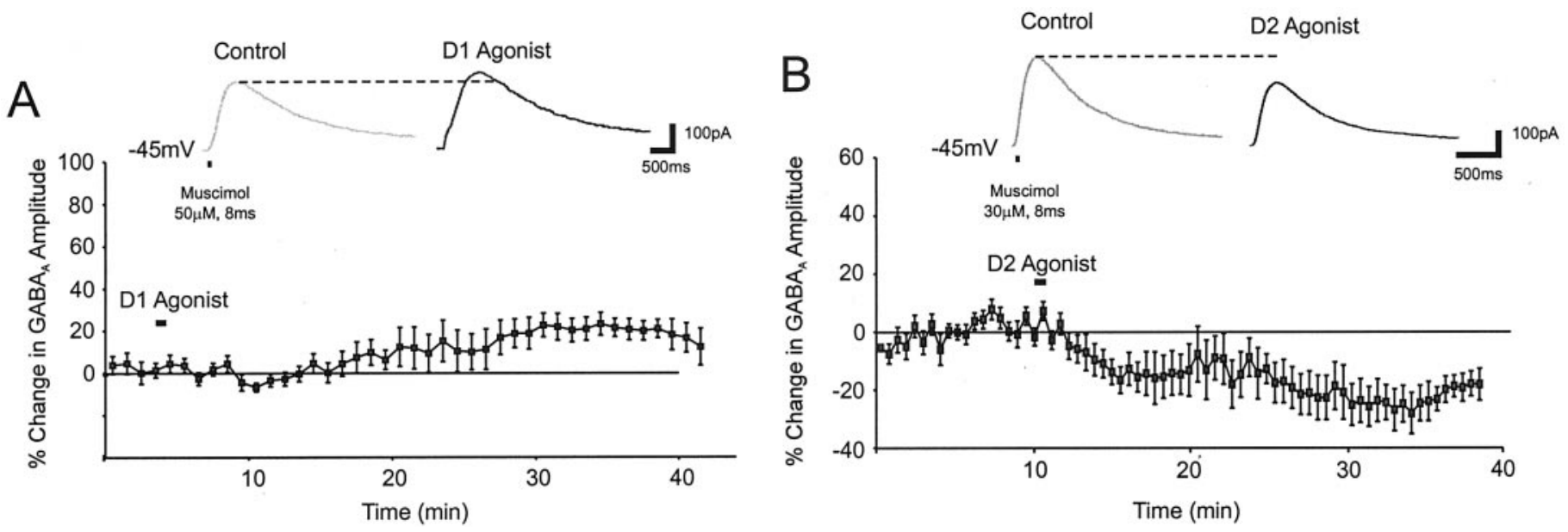

Figure 6. The effects of $\mathrm{D} 1$ and $\mathrm{D} 2$ agonists on the postsynaptic $\mathrm{GABA}_{\mathrm{A}}$ current. $A$, Top, Representative traces showing that the response to puff

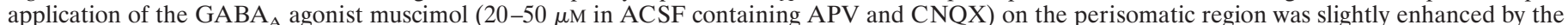

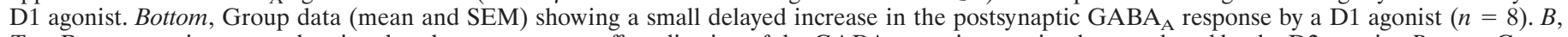
Top, Representative traces showing that the response to puff application of the GABA agonist muscimol was reduced by the D2 agonist. Bottom, Group data (mean and SEM) showing an abrupt decrease in the postsynaptic $\mathrm{GABA}_{\mathrm{A}}$ response induced by a D2 agonist $(n=10)$.

mine was smaller in magnitude than the effects of either D2 or D1 agonists alone. One reason for this was that dopamine reduced $\mathrm{R}_{\mathrm{in}}$, thereby counteracting any increase in eIPSCs. Another reason for this may be that D1 and D2 receptors were activated simultaneously in the dopamine condition but acted in opposite directions, making the overall effect of dopamine smaller than for either agonist alone. An important finding of the present study was that the time courses of the effects of D2 and D1 agonists were very different in that the D2-mediated reduction in eIPSC amplitude occurred quickly and subsided $\sim 30$ min after application (Fig. $2 B$ ), whereas the D1-mediated enhancement took $\sim 15$ min to develop fully and was stable for $>50 \mathrm{~min}$. The linear superposition of these two effects (as shown in Fig. 2D) reproduced the dopamine condition quite well, i.e., a lessened early reduction followed by a later persistent enhancement. However, although the bidirectional effect was observed by averaging the response of many neurons, $50 \%$ of individual neurons actually showed the clear biphasic effect, whereas $20 \%$ showed only a fast decrease, $10 \%$ a slow increase, and $20 \%$ were unchanged. One reason for this distribution may be that different neurons posses different densities of D1 and D2 receptors in different axodendro-somatic locations, allowing cell-specific or compartmental regulation of inhibition. One intriguing possibility is that experience-dependent processes could regulate the relative density of D1 and D2 receptors in PFC neurons and circuits, thereby differentially regulating inhibition.

A similar D2-mediated reduction followed by a D1-mediated enhancement has been observed for other types of PFC responses. A transient D2-mediated reduction and a delayed but very long-lasting D1-mediated increase has also been reported for excitability of pyramidal cells as measured by intracellular current injection (Yang and Seamans, 1996; Gulledge and Jaffe, 1998; Gorelova and Yang, 2000; Henze et al., 2000). Likewise, in PFC neurons, D2 agonists appear to reduce NMDA currents, whereas D1 agonists increase them (Zheng et al., 1999; Seamans et al., 2001). Therefore, such a transient D2-mediated reduction in intrinsic or synaptic currents followed by a prolonged D1mediated enhancement may be a common feature of dopaminergic modulation of PFC neurons.
One possible molecular mechanism is differential modulation of DARPP-32 by dopamine receptors. DARPP-32 is a dopamine and cAMP-regulated phosphoprotein that is a potent endogenous inhibitor of protein phosphatase-1 (Hemmings et al., 1987; Greengard et al., 1998; Svenningsson et al., 2000). D1 receptor activation converts DARPP-32 from its dephosphorylated, inactive form into its phosphorylated active form, whereas DARPP-32 is dephosphorylated and inactivated by D2 agonists (Nishi et al., 1997; Lindskog et al., 1999). Accordingly, in striatal neurons, D5 receptor activation enhanced GABA currents through PKA and protein phosphatase-1 (Yan and Surmeier, 1997), whereas activation of $D 2$ receptors inhibited $\mathrm{GABA}_{\mathrm{A}^{-}}$ mediated responses (Delgado et al., 2000). As such, D1 or D2 receptor activation may force DARPP-32 into one of two stable states that in turn produce relatively long-lived effects on synaptic currents (Nishi et al., 1997).

\section{Mechanisms of modulation}

The mechanisms responsible for the D1- and D2-mediated modulation of IPSCs were different. Dopamine via D1 receptors increased sIPSC frequency recorded in pyramidal neurons, suggesting an increase in interneuron excitability. Accordingly direct patch-clamp recordings from predominately fast-spiking interneurons have shown that dopamine (Zhou and Hablitz, 1999) via D1 receptors (Seamans et al., 2000; Gorelova, Seamans, and Yang, unpublished observations) depolarized interneurons and increased their excitability to depolarizing current pulses. In contrast, D1 agonists did not significantly affect mIPSC frequency or amplitude but slightly enhanced the postsynaptic response to muscimol, indicating that D1 receptor activation, in addition to increasing interneuron excitability, may produce a minor increase in the postsynaptic $\mathrm{GABA}_{\mathrm{A}}$ current.

In contrast, D2 agonists had no effect on sIPSC frequency or amplitude, suggesting that they did not regulate interneuron excitability. This finding is consistent with recent data showing that D2 agonists did not affect the excitability of interneurons to intracellular depolarizing current pulses (Seamans et al., 2000; Gorelova, Seamans, and Yang, unpublished observations). However, D2 agonists reduced eIPSC amplitude, reduced mIPSC 


\section{State 1 "D2-dominated"}

\section{State 2 "D1-dominated"}

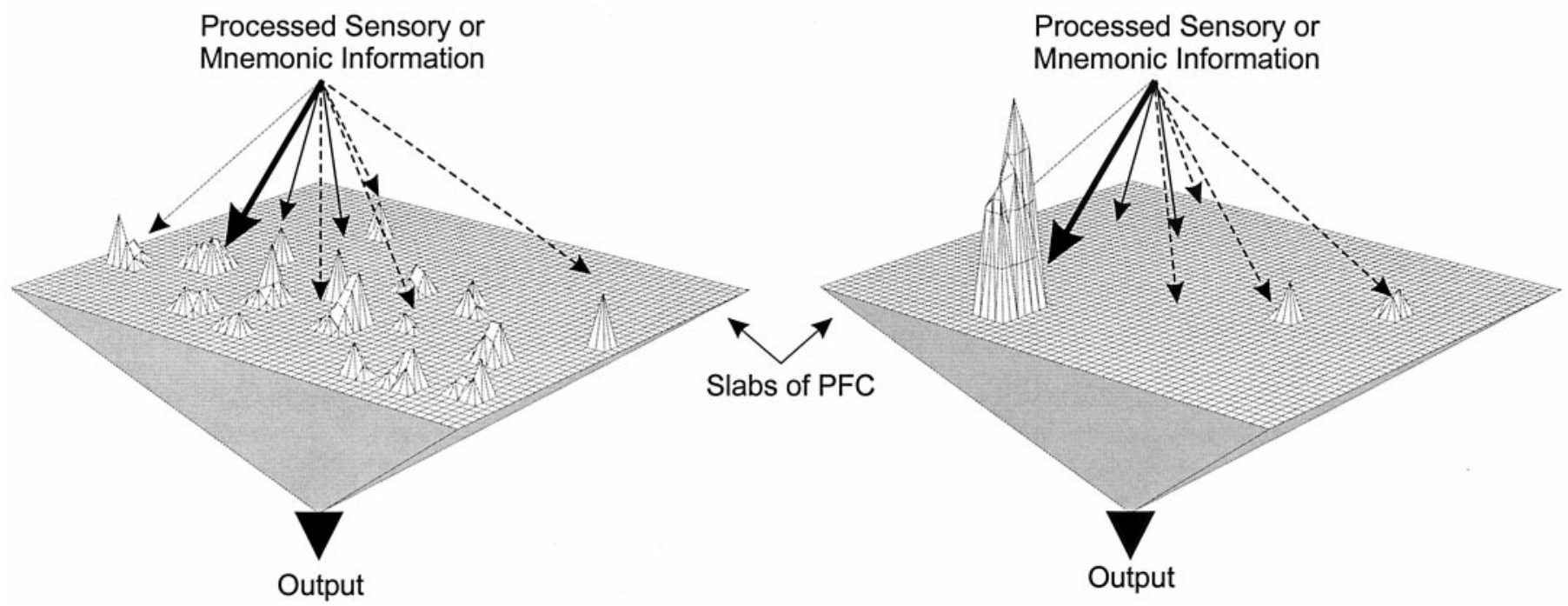

Figure 7. Theoretical implications of a bidirectional change in inhibition in the PFC. Left, In state 1, the D2 modulation predominates, and there is a net reduction in inhibition. As a result, multiple inputs impinging on the PFC have access to the working memory buffers, allowing multiple representations (i.e., sustained activity driven by recurrent excitation that encodes working memory information) to be held in PFC networks nearly simultaneously. Right, In state 2, the D1 modulation predominates, and there is a net increase in inhibition. As a result, inputs have difficulty accessing PFC networks. However, particularly strong inputs, which can overcome the effects of heightened inhibition, benefit from the simultaneous D1-mediated increases in long-lasting inward currents (i.e., persistent $\mathrm{Na}^{+}$and NMDA currents), which produce very active and stable network representations, even after the offset of the initiating stimulus (Yang and Seamans, 1996; Durstewitz et al., 2000; Seamans et al., 2001). In this way, dopamine may first allow an exploration of the input space (state 1), entertaining multiple network representations nearly simultaneously. Subsequent transition into state 2 shuts off the influence of weak inputs on PFC networks and strongly stabilizes one or a limited set of representations, which would then have complete control of PFC output.

frequency, shifted the mIPSC amplitude distribution leftward, and slightly reduced the response to muscimol. The reduction in mIPSC frequency is indicative of a presynaptic reduction in release probability, whereas the leftward shift in mIPSC amplitude and the reduced response to muscimol suggest a postsynaptic downregulation of $\mathrm{GABA}_{\mathrm{A}}$ receptor sensitivity or conductance.

The published effects of dopamine agonists on GABA release are also complex and dependent on a number of factors. PenitSoria et al. (1989) showed that D2 receptor activation reduced the electrically evoked release of preloaded $\left[{ }^{3} \mathrm{H}\right] \mathrm{GABA}$ in the PFC, whereas D1 agonists had no effect alone but facilitated the D2mediated inhibition (Rétaux et al., 1991). However, coactivation of D1 and D2 receptors increased the spontaneous release of preloaded [ $\left.{ }^{3} \mathrm{H}\right]$ GABA (Rétaux et al., 1990). In contrast, Grobin and Deutch (1998) showed that D2 but not D1 agonists increased GABA levels measured via microdialysis. One reason for the discrepant findings may be that dopamine has bidirectional and time-dependent effects on GABAergic IPSCs, as revealed in the present study. In addition, there may be age-dependent effects. Both cortical dopamine and GABA systems attain adult levels at an early age (e.g., postnatal day 10) (Miller, 1988; Leslie et al., 1991; Luhman and Prince, 1991; Srivastava et al., 1992). However, extensive changes in local synaptic circuitry within the PFC do occur in younger animals (Vincent et al., 1995; Benes et al., 1996), within the age range used in this and other electrophysiological studies. Assuming the results also hold in older animals, our data would predict that D1 agonists, by increasing interneuron excitability, should produce a delayed increase only in impulse-dependent release of GABA, whereas D2 agonists should quickly reduce both impulse-dependent and -independent release of GABA. However, one must bear in mind that D1 and D2 agonists also modulate a number of intrinsic and synaptic currents in pyramidal cells and interneurons (Yang and Seamans, 1996; Gulledge and Jaffe 1998; Yang et al., 1999; Zheng et al., 1999; Gorelova and Yang, 2000; Seamans et al., 2001), making the effect on GABA systems in vivo complex and difficult to predict.

\section{Functional implications}

Putative GABAergic interneurons recorded in vivo during oculomotor delayed response tasks show task-related activity similar to that of nearby pyramidal cells, whereas interneurons and pyramidal cells within different columns exhibit cross-directional tuning (Wilson et al., 1994; Rao et al., 1999). Blockade of GABA $_{\mathrm{A}}$ receptors by iontophoresis of bicuculline disrupts the spatial tuning of both pyramidal cells and interneurons exhibiting delayperiod activity (Rao et al., 2000), mainly because activity for stimuli in the nonpreferred location is increased. Hence, GABAergic activity may sharpen the memory fields of pyramidal neurons to "focus PFC cortical mechanisms to the task at hand" (Rao et al., 2000).

Dopamine via activation of D1 receptors has a complimentary influence on task-related neural activity in that it enhances delayand response-related firing much more than background activity (Sawaguchi et al., 1986, 1988, 1990a,b). Therefore, one possibility is that dopamine via D1 receptors increases the excitability of local interneurons and GABAergic conductances to sharpen the tuning of pyramidal cells and to focus activity on task-relevant items. However, the present data showed that a D2-mediated decrease in inhibition preceded the D1-mediated increase. Such a decrease in inhibition would allow multiple representations to be activated closely in time (Fig. 7), because even weak representa- 
tions could pop into the delay-active state easily (Durstewitz et al., 2000). Conversely, in a mode dominated by the D1-mediated enhancement in inhibition, weakly active representations fail to be maintained, and a single or limited number of strongly active representations become very stable to subsequent interfering inputs and noise (Durstewitz et al., 2000). In this way, dopamine may first allow an exploration of the input space (state 1), followed by transition into state 2 in which a limited set of representations are focused on and have complete control of PFC output (Fig. 7).

\section{REFERENCES}

Abekawa T, Ohmori T, Ito K, Koyama T (2000) D1 dopamine receptor activation reduces extracellular glutamate and GABA concentrations in the medial prefrontal cortex. Brain Res 867:250-254.

Benes FM, Vincent SL, Molloy R (1993) Dopamine-immunoreactive axon varicosities form nonrandom contacts with GABAimmunoreactive neurons of rat medial prefrontal cortex. Synapse 15:285-295.

Benes FM, Vincent SL, Molloy R, Khan Y (1996) Increased interaction of dopamine-immunoreactive varicosities with GABA neurons of rat medial prefrontal cortex occurs during the postweanling period. Synapse 23:237-245.

Bourdelais AJ, Deutch AY (1994) The effects of haloperidol and clozapine on extracellular GABA levels in the prefrontal cortex of the rat: an in vivo microdialysis study. Cereb Cortex 4:69-77.

Delgado A, Sierra A, Querejeta E, Valdiosera RF, Aceves J (2000) Inhibitory control of the GABAergic transmission in the rat neostriatum by D2 dopamine receptors. Neuroscience 95:1043-1048.

Durstewitz D, Kelc M, Güntürkün O (1999) A neurocomputational theory of the dopaminergic modulation of working memory functions. J Neurosci 19:2807-2822.

Durstewitz D, Seamans JK, Sejnowski TJ (2000) Dopamine-mediated stabilization of delay-period activity in a network model of prefrontal cortex. J Neurophysiol 83:1733-1750.

Erickson SL, Sesack SR, Lewis DA (2000) Dopamine innervation of monkey entorhinal cortex: postsynaptic targets of tyrosine hydroxylaseimmunoreactive terminals. Synapse 36:47-56.

Floran B, Floran L, Sierra A, Aceves J (1997) D2 receptor-mediated inhibition of GABA release by endogenous dopamine in the rat globus pallidus. Neurosci Lett 237:1-4.

Gorelova NA, Yang CR (2000) Dopamine D1/D5 receptor activation modulates a persistent sodium current in rat prefrontal cortical neurons in vitro. J Neurophysiol 84:75-87.

Greengard P, Nairn AC, Girault JA, Ouimet CC, Snyder GL, Fisone G, Allen PB, Fienberg A, Nishi A (1998) The DARPP-32/protein phosphatase-1 cascade: a model for signal integration. Brain Res Rev 26:274-284.

Grobin AC, Deutch AY (1998) Dopaminergic regulation of extracellular gamma-aminobutyric acid levels in the prefrontal cortex of the rat. J Pharmacol Exp Ther 285:350-357.

Gulledge AT, Jaffe DB (1998) Dopamine decreases the excitability of layer $\mathrm{V}$ pyramidal cells in the rat prefrontal cortex. J Neurosci 18:9139-9151.

Harsing Jr LG, Zigmond MJ (1997) Influence of dopamine on GABA release in striatum: evidence for D1-D2 interactions and non-synaptic influences. Neuroscience 77:419-429.

Hemmings HC, Walaas SI, Ouimet CC, Greengard P (1987) Dopaminergic regulation of protein phosphorylation in the striatum: DARPP32. Trends Neurosci 10:377-383.

Henze DA, Gonzalez-Burgos GR, Urban NN, Lewis DA, Barrionuevo G (2000) Dopamine increases excitability of pyramidal neurons in primate prefrontal cortex. J Neurophysiol 84:2799-2809.

Kawaguchi Y (1993) Groupings of nonpyramidal and pyramidal cells with specific physiological and morphological characteristics in rat frontal cortex. J Neurophysiol 69:416-431.

Kawaguchi Y, Kubota Y (1997) GABAergic cell subtypes and their synaptic connections in rat frontal cortex. Cereb Cortex 7:476-486.

Le Moine C, Gaspar P (1998) Subpopulations of cortical GABAergic interneurons differ by their expression of $\mathrm{D} 1$ and $\mathrm{D} 2$ dopamine receptor subtypes. Brain Res Mol Brain Res 58:231-236.

Leslie CA, Robertson MW, Cutler AJ, Bennett Jr JP (1991) Postnatal development of D1 dopamine receptors in the medial prefrontal cortex, striatum and nucleus accumbens of normal and neonatal 6-hydroxydopamine treated rats: a quantitative autoradiographic analysis. Dev Brain Res 62:109-114.

Lindskog M, Svenningsson P, Fredholm BB, Greengard P, Fisone G (1999) Activation of dopamine D2 receptors decreases DARPP-32 phosphorylation in striatonigral and striatopallidal projection neurons via different mechanisms. Neuroscience 88:1005-1008.
Luhman HJ, Prince DA (1991) Postnatal maturation of the GABAergic system in rat neocortex. J Neurophysiol 65:247-263.

Miller MW (1988) Development of projection and local circuit neurons in neocortex. In: Cereb cortex: development and maturation of cereb cortex (Peters A, Jones EG, eds), pp 133-175. New York: Plenum.

Muly EC, Szigeti K, Goldman-Rakic PS (1998) D1 receptor in interneurons of macaque prefrontal cortex: distribution and subcellular localization. J Neurosci 18:10553-10565.

Nishi A, Snyder GL, Greengard P (1997) Bidirectional regulation of DARPP-32 phosphorylation by dopamine. J Neurosci 17:8147-8155.

Paxinos G, Watson C (1982) The rat brain in stereotaxic coordinates. New York: Academic.

Penit-Soria J, Audinat E, Crepel F (1987) Excitation of rat prefrontal cortical neurons by dopamine: an in vitro electrophysiological study. Brain Res 425:263-274.

Penit-Soria J, Rétaux S, Maurin Y (1989) Effects of the stimulation of D1 and D2 dopaminergic receptors on the electrically induced release of gamma- $(3 \mathrm{H})$-aminobutyric acid in the prefrontal cortex of the rat. $\mathrm{C}$ R Acad Sci III 309:441-446.

Pirot S, Godbout R, Mantz J, Tassin JP, Glowinski J, Thierry AM (1992) Inhibitory effects of ventral tegmental area stimulation on the activity of prefrontal cortical neurons: evidence for the involvement of both dopaminergic and GABAergic components. Neuroscience 49:857-865.

Rao SG, Williams GV, Goldman-Rakic PS (1999) Isodirectional tuning of adjacent interneurons and pyramidal cells during working memory: evidence for microcolumnar organization in PFC. J Neurophysiol 81:1903-1916.

Rao SG, Williams GV, Goldman-Rakic PS (2000) Destruction and creation of spatial tuning by disinhibition: GABA(A) blockade of prefrontal cortical neurons engaged by working memory. J Neurosci 20:485-494.

Rétaux S, Besson MJ, Penit-Soria J (1990) D2 dopaminergic receptor activation enhances the spontaneous release of $3 \mathrm{H}-\mathrm{GABA}$ in the prefrontal cortex of rats, in vitro. The facilitating role of D1 dopaminergic receptors. C R Acad Sci III 311:295-300.

Rétaux S, Besson MJ, Penit-Soria J (1991) Opposing effects of dopamine D2 receptor stimulation on the spontaneous and the electrically evoked release of $[3 \mathrm{H}] \mathrm{GABA}$ on rat prefrontal cortex slices. Neuroscience 42:61-71.

Sawaguchi T, Matsumura M, Kubota K (1986) Dopamine modulates neuronal activities related to motor performance in the monkey prefrontal cortex. Brain Res 371:404-408.

Sawaguchi T, Matsumura M, Kubota K (1988) Dopamine enhances the neuronal activity of spatial short-term memory performance in the primate prefrontal cortex. Neurosci Res 5:465-473.

Sawaguchi T, Matsumura M, Kubota K (1990a) Catecholamine effects on neuronal activity related to a delayed response task in monkey prefrontal cortex. J Neurophysiol 63:1385-1400.

Sawaguchi T, Matsumura M, Kubota K (1990b) Effects of dopamine antagonists on neuronal activity related to a delayed response task in monkey prefrontal cortex. J Neurophysiol 63:1401-1412.

Seamans JK, Gorelova N, Durstewitz D, Yang CR (2000) Bidirectional regulation of GABAergic inhibition in the prefrontal cortex by dopamine. Soc Neurosci Abstr 30:1430.

Seamans JK, Durstewitz D, Christie B, Stevens CF, Sejnowski TJ (2001) Dopamine D1/D5 receptor modulation of excitatory synaptic inputs to layer V prefrontal cortex neurons. Proc Natl Acad Sci USA 98:301-306.

Seeman P, VanTol HHM (1994) Dopamine receptor pharmacology. Trends Pharmacol 15:264-270.

Sesack SR, Snyder CL, Lewis DA (1995) Axon terminals immunolabeled for dopamine or tyrosine hydroxylase synapse on GABAimmunoreactive dendrites in rat and monkey cortex. J Comp Neurol 363:264-280.

Sesack SR, Hawrylak VA, Melchitzky DS, Lewis DA (1998) Dopamine innervation of a subclass of local circuit neurons in monkey prefrontal cortex: ultrastructural analysis of tyrosine hydroxylase and parvalbumin immunoreactive structures. Cereb Cortex 8:614-622.

Shi WX, Zheng P, Liang XF, Bunney BS (1997) Characterization of dopamine-induced depolarization of prefrontal cortical neurons. Synapse 26:415-422.

Srivastava LK, Morency MA, Mishra RK (1992) Ontogeny of dopamine D2 receptor mRNA in rat brain. Eur J Pharmacol 225:143-150.

Svenningsson P, Lindskog M, Ledent C, Parmentier M, Greengard P, Fredholm BB, Fisone G (2000) Regulation of the phosphorylation of the dopamine- and cAMP-regulated phosphoprotein of $32 \mathrm{kDa}$ in vivo by dopamine D1, dopamine D2, and adenosine A2A receptors. Proc Natl Acad Sci USA 97:1856-1860.

Uylings HBM, van Eden CG (1990) Qualitative and quantitative comparison of the prefrontal cortex in rat and in primates, including humans. Prog Brain Res 85:31-62. 
Verney C, Alvarez C, Geffard M, Berger B (1990) Ultrastructural double labelling study of dopamine terminals and GABA-containing neurons in rat anteromedial cerebral cortex. Eur J Neurosci 2:295-298.

Vincent SL, Pabreza L, Benes FM (1995) Postnatal maturation of GABA-immunoreactive neurons of rat medial prefrontal cortex. J Comp Neurol 355:81-92.

Wilson FA, O'Scalaidhe SP, Goldman-Rakic PS (1994) Functional synergism between putative gamma-aminobutyrate-containing neurons and pyramidal neurons in prefrontal cortex. Proc Natl Acad Sci USA 91:4009-4013.

Yan Z, Surmeier DJ (1997) D5 dopamine receptors enhance $\mathrm{Zn}^{2+}$ sensitive GABA(A) currents in striatal cholinergic interneurons through a PKA/PP1 cascade. Neuron 19:1115-1126.
Yang CR, Seamans JK (1996) Dopamine D1 receptor actions in layer V-VI rat prefrontal cortex neurons in vitro: modulation of dendriticsomatic signal integration. J Neurosci 16:1922-1935.

Yang CR, Seamans JK, Gorelova NA (1999) Developing a neuronal model of the pathophysiology of schizophrenia based on the nature of the electrophysiological actions of dopamine in the prefrontal cortex. Neuropsychopharmacology 21:161-194.

Zheng P, Zhang XX, Bunney BS, Shi WX (1999) Opposite modulation of cortical $N$-methyl-D-aspartate receptor-mediated responses by low and high concentrations of dopamine. Neuroscience 91:527-535.

Zhou FM, Hablitz JJ (1999) Dopamine modulation of membrane and synaptic properties of interneurons in rat cerebral cortex. J Neurophysiol 81:967-976. 